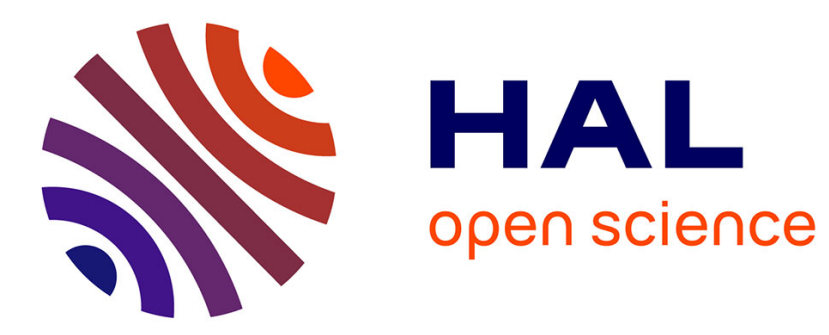

\title{
Prerequisites for the Antitumor Vaccine-Like Effect of Chemotherapy and Radiotherapy
}

\author{
Dalil Hannani, Antonella Sistigu, Oliver Kepp, Lorenzo Galluzzi, Guido \\ Kroemer, Laurence Zitvogel
}

\section{- To cite this version:}

Dalil Hannani, Antonella Sistigu, Oliver Kepp, Lorenzo Galluzzi, Guido Kroemer, et al.. Prerequisites for the Antitumor Vaccine-Like Effect of Chemotherapy and Radiotherapy. Cancer Journal, 2011, 17, 10.1097/PPO.0b013e3182325d4d . hal-02047421

\section{HAL Id: hal-02047421 \\ https://hal.science/hal-02047421}

Submitted on 17 Dec 2020

HAL is a multi-disciplinary open access archive for the deposit and dissemination of scientific research documents, whether they are published or not. The documents may come from teaching and research institutions in France or abroad, or from public or private research centers.
L'archive ouverte pluridisciplinaire $\mathbf{H A L}$, est destinée au dépôt et à la diffusion de documents scientifiques de niveau recherche, publiés ou non, émanant des établissements d'enseignement et de recherche français ou étrangers, des laboratoires publics ou privés. 


\title{
Prerequisites for the Antitumor Vaccine-Like Effect of Chemotherapy and Radiotherapy
}

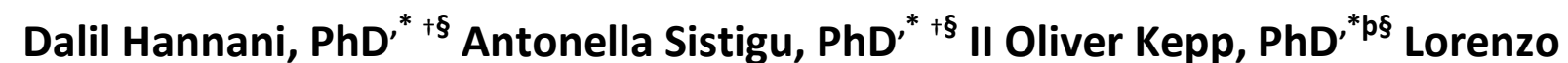 \\ Galluzzi, PhD ${ }^{*{ }^{*} \S}$ Guido Kroemer, MD, PhD ${ }^{, * p q l L^{* * p p}}$ and Laurence Zitvogel, MD, PhD ${ }^{* \mathrm{p} \S}$
}

From the *Institut Gustave Roussy, Villejuif, France; †INSERM, U1015, Villejuif, France; ¥INSERM, U848, Villejuif, France; §Universite' Paris Sud-XI, Villejuif, France; I|Istituto Superiore di Sanita', Rome, Italy; ПMetabolomics Platform, Institut Gustave Roussy, Villejuif, France; LCentre de Recherche des Cordeliers, Paris, France; **Pôle de Biologie, Hoo^pital Europe'en Georges Pompidou, Paris, France; †+Universite' Paris Descartes, Paris, France.

Correspondance: Laurence Zitvogel, MD, PhD, INSERM, U1015, Institut Gustave Roussy, F-94805

Villejuif, Paris, France. E-mail: zitvogel@igr.fr.

Abstract: For a long time, anticancer therapies were believed to work (and hence convey a therapeutic benefit) either by killing cancer cells or by inducing a permanent arrest in their cell cycle (senescence). In both scenarios, the efficacy of anticancer regimens was thought to de-pend on cancer cellYintrinsic features only. More recently, the impor-tance of the tumor microenvironment (including stromal and immune cells) has been recognized, along with the development of therapies that function by modulating tumor cellYextrinsic pathways. In particu-lar, it has been shown that some chemotherapeutic and radiotherapeutic regimens trigger cancer cell death while stimulating an active immune response against the tumor. Such an immunogenic cell death relies on the coordinated emission of specific signals from dying cancer cells and their perception by the host immune system. The resulting tumor-specific immune response is critical for the eradication of tumor cells that may survive therapy. In this review, we discuss the molecular mechan-isms that underlie the vaccine-like effects of some chemotherapeutic and radiotherapeutic regimens, with particular attention to the signaling pathways and genetic elements that constitute the prerequisites for im-munogenic anticancer therapy.

Key Words: Calreticulin, HMGB1, NLRP3, TLR4, ATP, dendritic cells 


\section{IMMUNOGENIC TUMOR CELL DEATH}

Although the armamentarium of anticancer therapies is being constantly ameliorated, the number of people succumbing to cancer has been predicted to drastically rise in the future (www.who.int/cancer). This trend basically reflects the facts that efficient therapies for some prominent neoplasms such as lung cancer (which now is the leading cause of cancer-related deaths worldwide) are still missing and that current anticancer regi-mens are often associated with the insurgence of resistance and therapeutic failure. ${ }^{1}$ To counteract this dreadful tendency, further insights into the molecular mechanisms underlying the resistance of cancer cells to conventional therapy and into the signaling pathways that govern the host-tumor crosstalk are urgently awaited. This type of information will allow not only for the refinement of the current therapeutic arsenal, but also for a better stratification of cancer patients and the de-velopment of personalized anticancer therapies.

The current clinical approach to cancer most frequently involves surgery (whenever possible) alone or in association with a single-agent or combinatorial treatment based on che-motherapy or radiotherapy. Intriguingly, some cancers can be cured by conventional regimen (such as breast, colon, testicular, prostate, head and neck cancers, Hodgkin and follicular lym-phoma, etc.), whereas others still remain a major medical chal-lenge (such as lung and pancreatic cancers), suggesting that the intrinsic properties of the tumor and/or the specificity of the cytotoxic drugs matter. Minimal residual disease or incom-plete eradication of tumor (stem) cells associated with the arousal of chemoresistant and/or radioresistant metastases ${ }^{1}$ questioned the bases of our current reasoning. Thus, to improve the clinical outcome of anticancer therapies, it is of the utmost importance to understand how therapy-resistant tumor cells can be efficiently targeted and how therapeutic failure can be predicted.

For a long time, the field of clinical oncology was domi-nated by the notion that efficient anticancer therapies would work exclusively on tumor cells, either by inducing their apo-ptotic demise (cytotoxicity) and immunologically silent clear-ance or by permanently arresting their cell cycle progression (cytostasis). Moreover, several anticancer compounds were known to induce different degrees of immunosuppression, reinforcing the belief that the host immune system plays no role in the fight against transformed cells. Even the official guidelines for-mulated in 1975 by the National Institutes of Health recom-mended that the efficacy of novel anticancer strategies should be evaluated on human cancers xenotransplanted in immuno-deficient mice. ${ }^{2}$ More recently, it has been shown that (i) cancer cells engage in a strict crosstalk with their microenvironment (the tumor stroma, including fibroblasts and endothelial and immune cells such as macrophages) and that this interaction can be specifically targeted to induce tumor regression ${ }^{3}$; that (ii) highly efficient anticancer regimens can kill tumor cells through nonapoptotic cell death subroutines ${ }^{4}$; and that (iii) apoptosis can also occur in an immunogenic fashion, leading to the elici-tation of an anticancer immune response. ${ }^{5}$

Such an immunogenic cell death (ICD) involves the trans-fer of tumor-derived antigens to immune cells that stimulate a tumor-specific immune response. This is critical for the eradi-cation of residual cancer (stem) cells as it operates irrespective of their resistance to therapy. ${ }^{2}$ Experiments in suitable animal as genetic interventions whereby BAX, BAK, and/or caspase 8 are removed or depleted, blocks CRT exposure and abolishes the tumor-vaccinating effect of cells undergoing ICD. 6,15 
Third, approximately 5\% to $10 \%$ of the endogenous CRT pool is exposed together with ERp57 at the surface of dying cells via SNAP and NSF attachment receptor (SNARE)Y dependent exocytosis. This occurs well before plasma mem-brane permeabilization (which occurs as the final step of apoptosis) and also precedes the translocation of phosphati-dylserine (PS) from the inner to the outer leaflet of the plasma membrane. Phosphatidylserine is the prototypic eat-me sig-nal of apoptotic cells (although it has been implicated also in nonapoptotic cell death), ${ }^{20,21}$ and the kinetics of its exposure might affect the switch between the silent removal of dying cells by macrophages and the initiation of a cognate immune response by DCs. ${ }^{16}$ The receptor that is responsible for antigen uptake by DCs upon CRT binding remains to be deter-mined. Possible candidates include the major CRT receptor CD91 as well as other CRT-interacting proteins such as scav-enger receptor A, scavenger receptor expressed on endothelial cell I, ${ }^{22}$ CD40 ligand, tumor necrosis factorYrelated apoptosis-inducing ligand (tumor necrosis factorYrelated apoptosis in-ducing ligand), or CD95/FAS ligand. ${ }^{23}$ The CRT-driven uptake of tumor antigens by DCs is per se insufficient to elicit an anti-tumor immune response as internalized antigens must be pro-cessed and re-exposed for the cross-priming of CD4+ and CD8+ T lymphocytes. This implies that other signaling path-ways are involved in ICD.

A systematic study of the response to CDAMPs of dis-tinct Toll-like receptors (TLRs) on naive T cells revealed that TLR4 is both required and sufficient for efficient antigen pre-sentation by DCs. ${ }^{24}$ Among other proteins, TLR4 binds the nonYhistone chromatinYbinding nuclear protein high-mobility group box 1 (HMGB1), leading to the activation of the down-stream effector myeloid differentiation primary response 88 (MYD88). ${ }^{24}$ This inhibits the fusion between lysosomes and antigen-containing phagosomes, thus facilitating antigen pro-cessing and presentation to $T$ cells. High-mobility group box 1 also stimulates the neosynthesis of proYIL-1A ${ }^{25}$ but per se does not serve as a DC maturation signal. ${ }^{24}$ For a long time, HMGB1 has been thought to exert a proinflammatory function exclu-sively during necrosis, ${ }^{26}$ but recent evidence indicates that it also gets released during the late stages of apoptosis. ${ }^{27}$ The re-lease of HMGB1 from tumor cells succumbing to ICD can be blocked by Z-VADfmk and hence depends on the activation of caspases. ${ }^{24,27}$ This process manifests with a dual kinetics whereby HMGB1 first translocates from the nucleus to the cy-toplasm and then, following the breakdown of the plasma membrane, gets released into the extracellular space. ${ }^{8}$ Further insights into the molecular mechanisms that underlie HMBG1 release are missing. However, the addition of recombinant CRT or HMGB1 to dying cancer cells does not suffice to stimulate the presentation of tumor antigens by $\mathrm{DCs},{ }^{28,29}$ implying that additional signals are required for the immunogenicity of cell death.

The vaccine-like effect of ICD relies on the elicitation of an IFN-FYpolarized T-cell response, which in turn requires the function of the NLRP3 inflammasome, a multiprotein caspase 1Yactivating complex ${ }^{30}$ Caspase 1 activation is critical for acti-vating an antitumor immune response as it catalyzes the pro-teolytic maturation of IL-1A. ${ }^{31}$ One of the most abundant factors that activate the NLRP3 inflammasome is ATP, ${ }^{32}$ andVat least in DCsVit does so by binding to the purinergic P2RX7 recep-tor on the cell surface. ${ }^{10}$ ATP also constitutes a CDAMP, as it gets released during the final steps of cell death, possibly via voltage-gated hemichannels of the pannexin 1 or connexin type. ${ }^{33}$ Accordingly, the depletion of intracellular or extracel-lular ATP in cells succumbing to ICD abolishes the develop-ment of an IFN-FYpolarized response, and P2RX7-deficient mice fail to mount an immune response against syngenic can-cer cells succumbing to ICD. ${ }^{10}$ Intriguingly, ATP also serves as a "find me" signal for the attraction of immune cells. ${ }^{34}$ Alto-gether, these observations highlight the multifaceted and criti-cal role of ATP for the vaccine-like effects of ICD inducers.

\section{SPATIOTEMPORAL CODE}


The spatially and temporally regulated emission of immu-nogenic factors from dying tumor cells accounts for the re-cruitment and activation of immune cells to tumor bed and governs the immune response to cancer cells undergoing ICD (Fig. 1). Thus, the stress conditions that cancer cells confront during chemotherapy and radiotherapy determine whether the subsequent wave of cell death will elicit an antitumor immune response or rather will remain immunologically silent. Normally, cells attempt to cope with stress by arresting normal activities and by activating a series of cytoprotective mechanisms that aim at reestablishing homeostasis. For instance, stressed cells normally arrest protein synthesis, activate DNA repair path-ways, and up-regulate factors for the handling of unfolded pro-teins as well as antioxidant defenses. This is accompanied by alterations of the surface proteome that, in the case of ICD, account for the recognition by immune cells and by the emis-sion of soluble mediators with chemotactic and antichemotactic properties. This is crucial for the "selection" and differentiation/ maturation of engulfing cells, which in turn dictates the immu-nogenic or tolerogenic outcome of cell death.

In this sense, the exposure of the DC-specific eat-me sig-nal CRT (well before that of PS) paralleled by the disclosure of other, hitherto uncharacterized "don't eat me" signals (such as CD47 ${ }^{35 Y 37}$ ) facilitates the recognition and uptake of dying tumor cells by DCs rather than by macrophages. Other authors have described additional molecular components exposed by dying cells that should be recognized for engulfment by specific DC subsets (such as CLEC9A/DNGR1 and HSP70/90) to elicit adaptive immune responses. ${ }^{29,38,39}$ However, additional stimuli released by dying tumor cells in the proximity of DCs are indispensable for the induction of a tumor-specific immune response. Thus, HMGB1 and ATP facilitate antigen processing/presentation and the release of IL-1A, which is necessary for IFN-FYpolarized T-cell responses. Based on these observations, the spatially restricted and temporally ordered appearance of CRT, HMGB1, and ATP might constitute a "key" that would precisely fit into a series of pattern recognition receptors expressed by DCs (the "lock") for the conversion of nonimmunogenic into ICD and for the elicitation of an anti-cancer immune response. $^{12}$

\section{THE PERCEPTION OF IMMUNOGENIC CELL DEATH BY THE IMMUNE SYSTEM}

Oncogenesis is a multistep mechanism that also involves an escape from immunosurveillance; that is, often cancer cells that sustain tumor growth are poorly immunogenic (immu-noselection) and/or they actively inhibit immune functions (immunosubversion). ${ }^{40}$ In this context, there are (at least) 2 different pathways whereby the immune system can be re-cruited against tumors: via direct immunomodulatory thera-pies that relieve immunosuppression or indirectly upon the induction of ICD.

By shaping T-cell responses, DCs are the first-line deci-sion makers of the innate immune system, and their role in immunogenic chemotherapy has been deeply investigated. Ex-periments in transgenic mice that express the diphtheria toxin receptor under the control of a DC-specific promoter (allowing for in vivo DC depletion) ${ }^{9}$ revealed the essential role of DCs in the perception and decoding of "come and get me" signals emitted by dying tumor cells during ICD. ${ }^{24}$ Similarly, the in vivo depletion of CD8+ T cells with specific antibodies has been instrumental to highlight the critical role of this lympho-cyte subset for the vaccine-like effect of chemotherapy and radiotherapy in a large panel of murine tumor models, including CT26 colon cancer, EL4 thymomas, TS/A mammary carci-nomas, MCA205 fibrosarcomas, Glasgow osteosarcoma osteosarcomas, ${ }^{11,24}$ and spontaneous methylcholanthrene-induced sarcomas. ${ }^{24,41}$ In line with these observations, CD8+ $\mathrm{T}$ cells have been shown to mediate potent anticancer immune effects in clinical settings, for instance, in colorectal tumors, where im-mune infiltration might serve as a prognostic factor. ${ }^{42}$ 
Moreover, it has recently been shown that a precise orchestration of the T-cell response is required for immune effectors to eradicate tumors. ${ }^{43}$ In this context, the IL-1AYdependent activation of IL$17 Y$ secreting $\mathrm{F} / \mathrm{C} \mathrm{T}$ cells had to precede the infiltration of tumors by Tc1 lymphocytes for the efficacy of immunogenic chemotherapy in vivo. ${ }^{43}$ Thus, a finely regulated crosstalk be-tween components of the innate (DCs) and cognate (F/C and CD8+ T cells) immune system is required for cell death to be perceived as immunogenic, for the elicitation of an anticancer immune response, and for complete tumor eradication leading to therapeutic success (Fig. 2). However, how resident macrophages and/or adverse inflammatory monocytes, which contribute to the proangiogenic and protumoral microenvironment and dominate the scenario before chemotherapy, become "transformed" and/or "overruled" by a subset of antigen presenting cells capable of eliciting a protective anticancer responses in the context of ICD remains to be established.

\section{IMMUNOGENIC ANTICANCER CHEMOTHERAPY}

The current definition of immunogenic chemotherapy is based on the ability of a limited array of antineoplastic drugs to elicit ICD rather than the stereotypical, immunologically silent or even tolerogenic apoptotic pathway. A plethora of precli-nical ${ }^{44 Y 51}$ and clinical ${ }^{52}$ studies revealed that DCs can take up apoptotic tumor cells and cross-present the internalized anti-gens on major histocompatibility complex class I molecules to CD8+ T cells, thus eliciting a productive immune response.

These studies suggest that the immunogenic outcome of cell death is influenced (among other factors) by the nature of the tumor cell as well as by the type of cell death inducer. In this context, a wide arsenal of stimuli including ER stressors (thapsigargin, tunicamycin, brefeldin), lysosometargeting agents (bafilomycin A1), mitochondrion-targeting compounds (arse-nite, betulinic acid, ceramide), proteasome inhibitors (MG132, lactacystin, ALLN), and DNA damaging molecules (Hoechst 33 342, camptothecin, etoposide, mitomycin) is per se not immu-nogenic. ${ }^{5}$ Conversely, some cytotoxic chemicals that are currently used for anticancer therapy such as anthracyclines, oxaliplatin (but not cisplatin), and cyclophosphamide induce a type of cell death that is immunogenic, yet is accompanied by all known biochemical and morphologic hallmarks of apoptosis. ${ }^{53,54}$ Tumor cells that have been killed in vitro with such chemothera-peutic agents elicit a vaccine-like effect when they are injected subcutaneously into immunocompetent mice. This leads to the long-term protection of mice against subsequent rechallenges with live tumor cells of the same type. Cancer cells respond to DNA damaging agents (which constitute an important class of clinically used chemotherapeutics) with a complex signaling pathway that either allows for DNA repair (if the damage is lim-ited) or engages apoptotic mechanisms (if the damage is exces-sive). ${ }^{55}$ Prominent players of the DNA damage response include the ataxia telangiectasia mutated (ATM) and the ATM-related kinases, checkpoint kinases 1 and 2 (CHK1 and CHK2), ${ }^{56}$ and the tumor suppressor protein TP53. ${ }^{57}$

Beyond their role in the DNA damage response, ATM and CHK1 are known to induce the expression of natural killer (NK) cell group 2D (NKG2D) ligands, thus sensitizing tumor cells to NKmediated lysis. ${ }^{58761}$ In addition, TP53 might mediate NKG2D ligand-independent immunogenic effects by inducing cell senescence, a status that has been surmised to be recognized by NK cells and macro-phages, leading to tumor eradication. ${ }^{62}$ Recently, multiple chemotherapeutic agents have been shown to up-regulate the expression of mannose-6-phosphate receptors on the surface of tumor cells, thereby promoting a perforin-independent in-crease in the permeability to granzyme $B$ released by $C D 8+$ lymphocytes. ${ }^{63}$ Altogether, these observations suggest that mul-tiple anticancer agents that are currently used in the clinical set-ting induce or at least facilitate ICD. 
Some chemotherapeutic agents improve anticancer immu-nity by exerting direct immunomodulatory effects. For instance, cyclophosphamideVwhich is widely used against lymphomas and leukemiaVselectively reduces the frequency of tumor-induced regulatory $T$ cells, ${ }^{64}$ induces the differentiation of $T_{H} 17$ cells, ${ }^{65}$ enhances the long-term survival and prolifera-tion of lymphocytes, ${ }^{66,67}$ and resets DC homeostasis. ${ }^{54,68 Y 71}$

Along similar lines, imatinibVa tyrosine kinase inhibitor used in bcr/abl and Kit-induced malignanciesVactivates NK-dependent antitumor effects in mouse models ${ }^{72}$ and stimu-lates the NKmediated secretion of IFN-F in patients with gastrointestinal stromal tumor, thus improving longterm sur-vival. ${ }^{73}$ Thus, several chemotherapeutic agents provide thera-peutic benefits not only via tumor cellYintrinsic, on-target effects but also by modulating immune responses in an off-target fashion.

\section{RADIOTHERAPY AS A POTENT ANTICANCER VACCINE INDUCER}

Focused ionizing radiations induce cancer cell death upon the induction of DNA damage and the overgeneration of re-active oxygen species. ${ }^{74}$ For many years, the direct cytotoxic effect of radiotherapy has been considered as the sole determi-nant of its therapeutic success. However, multiple lines of evi-dence have accumulated suggesting that the therapeutic effects of radiotherapy cannot be accounted for by tumor cell death alone and hence might dependVat least in partVnot only on endothelial cells but also on the host immune system. ${ }^{75,76}$

Thus, radiotherapy appears to be more efficient in immuno-competent mice than in their immunodeficient counterparts. ${ }^{77}$ Moreover, the irradiation of primary tumors is known to in-hibit the growth of nonirradiated metastases that are localized at distant sites (a phenomenon known as "abscopal effect"). ${ }^{75}$ In line with this notion, the irradiation of primary 4T1 tumors (mouse breast cancer that spontaneously metastasizes) induced a CD8+ T cellYmediated immune response that controlled the growth of lung micrometastases when combined with an in-hibitor of cytotoxic $T$ lymphocyteYassociated antigen 4 (CTLA-4 receptors (to overcome tumor-induced T-cell tolerance).$^{78}$ Recently, these findings have been corroborated in other mu-rine models of cancer, namely, in TSA-derived breast can-cer and MCA-38Yderived colon carcinoma. In these settings, fractioned radiotherapy (but not single dose) combined to a CTLA-4Yblocking antibody led to potent abscopal effects that were paralleled by the production of consistent levels of IFN-F. ${ }^{79}$ Importantly, the frequency of CD8+ T cells elicited by radiotherapy appears to correlate with the intensity of the abscopal effect. Interestingly, radiotherapy influences the chemokine pattern of the tumor microenvironment (promot-ing CXCL16 secretion by irradiated tumor cells), facilitating the entry of effector CD8+CXCR6+ T cells into irradiated tu-mor beds. ${ }^{80}$ Altogether, these studies demonstrate that radiotherapy induces a $\mathrm{T}$ cellYdependent antitumor effect, by inducing and/or recruiting tumor-specific T cells into the tumor bed. ${ }^{81,82}$

Recently, we have demonstrated that tumor cells succumbing upon irradiation elicit a cognate tumor-specific response when injected subcutaneously into syngenic mice, thereby exerting a vaccine-like effect and protecting mice against subsequent chal-lenges with living tumor cells of the same type. ${ }^{6,7}$ Irradiation-induced ICD, which might account for, at least part of, the abscopal effect, $^{83,84}$ also turned out to rely on the preapoptotic exposure of CRT and the TLR4/Myd88 pathway (see above). Alternatively, it has been suggested that dormant antitumor im-munity might get reactivated by radiotherapy-induced inflammation and cytokine release, which together would trigger the recruitment of T cells into the tumor bed. ${ }^{80,85}$ Irrespective of the fact that the molecular mechanisms underlying the abscopal ef-fect remain poorly understood, radiotherapy appears as a potent trigger of ICD. 


\section{GENETIC BACKGROUND AND CLINICAL OUTCOME}

During ICD, TLR4 and P2RX7 on DCs are critical for sensing and decoding the immunogenic message conveyed by the release of HMGB1 and ATP, respectively. ${ }^{10,12,24}$ Both TLR4 and P2RX7 present several nonsynonymous single nucleotide polymorphisms, ${ }^{86,87}$ and loss-of-function TLR4 and P2RX7 mutants (Asp299Gly and Gly496Ala, respectively) display low ligand-binding affinity. In line with the fact that TLR4 plays a critical role during ICD (see above), the TLR4 Asp299Gly allele as been shown to negatively affect the progression-free survival of breast cancer patients who received anthracycline-based adjuvant chemotherapy ${ }^{24}$ as well as of patients bearing colorectal cancers that were treated with oxaliplatin-based regi-mens. ${ }^{88}$ Furthermore, among breast cancer patients who carried wild-type TLR4, the P2RX7 Gly496Ala allele was associated with shortened progression-free survival. ${ }^{10}$ These results strongly suggest that the defect in the molecular mechanisms by which ICD is perceived by the immune system limits the efficacy of anticancer chemotherapy. This also provides further support to the concept that anticancer immune responses and hence all the genetic and environmental factors that affect such responsesVare crucial for therapeutic success.

In view of these considerations, it is tempting to specu-late that detailed information on the patient and tumor genetic background would allow for the design of tailored anticancer regimens with optimal efficacy and limited adverse effects. In particular, such information might (at least partially) predict the proficiency of a tumor to undergo ICD and elicit a cog-nate immune response and, if required, suggest the develop-ment of interventions aimed at restoring the immunogenicity of cell death. For instance, defects in the ER stress module that is required for CRT exposure during CRT might be cor-rected by the direct absorption of recombinant CRT to the tumor. ${ }^{6}$ Along similar lines, TLR4 loss-of-function mutations (which result in the deficient perception of HMGB1-conveyed signals) might be compensated by combining chemotherapy with alternative TLR agonists or with lysosomal inhibitors such as chloroquine, ${ }^{24}$ whereas defects in $\mathrm{P} 2 \mathrm{RX} 7$ signaling might be reverted by the administration of exogenous IL- $1 A^{10}$ or apyrase inhibitors.

Alternative approaches for the elicitation of an antican-cer immune response focus on the reversal of tumor-induced tolerance by means of immunomodulatory agents such as mo-noclonal antibodies targeting suppressive pathways (such as CTLA-4, PD-1, Lag3, Tim-3) or engaging activating recep-tors (such as CD40, CD27, 4-1BB), cytokines, and cell based-approaches ( $T$ and DC) in combination with conventional therapies. ${ }^{89} 91$ In preclinical models, these strategies have been shown to enhance the vaccine-like effect of both chemothera-peutic and radiotherapeutic regimens, thereby constituting pro-mising approaches. ${ }^{91,79}$ Gulley and colleagues ${ }^{92}$ reported that, in prostate cancer patients, the combination of radiotherapy with an admixture of a recombinant vaccine against prostate-specific antigen (PSA) and B7.1 costimulatory molecules in-duced a significant increase in PSA-specific and MUC1-specific T cells. The expansion of MUC1-specific T cells indicates that a tumor antigen cross-priming occurs in vivo following radio-therapy. Brody and colleagues reported a phase I/II trial where low-dose radiotherapy combined with in situ TLR9 agonists induced lymphoma remission, not only at the site of the treated lesion but also at distant sites, associated with detectable an-ticancer T-cell responses. ${ }^{93}$

Taken together, these studies suggest that efficient anti-cancer regimens should combine immunogenic chemotherapy or radiotherapy with immunomodulatory agents that overcome tumor-induced immunosuppression. Moreover, whenever re-quired, the defects in the molecular machinery for the execution and perception of ICD should be compensated to obtain the complete eradication of tumors and long-term tumor-free sur-vival (Fig. 3). 


\section{PERSPECTIVES}

As we have discussed above, some (but not all) chemo-therapeutic and radiotherapeutic regimens induce the immu-nogenic death of tumor cells that, in specific circumstances, lead to the elicitation of a potent anticancer immune response. This vaccine-like effect is critical for both therapeutic success and long-term tumor-free survival. The ability of anticancer drugs to induce an ER-stress response that precedes cell death, the intrinsic capacity of tumor cells to emit immunogenic CDAMPs in a defined spatiotemporal order, and the ability of the host to perceive these signals and to overcome tumor-induced immunosuppression appear as fundamental prerequisites for the vaccine-like effect of radiotherapy or chemotherapy. We believe that future anticancer regimens should be tailored to each pa-tient and tumor's genetic background to take into account all these elements, as this will result in combination therapies with optimal cytotoxic and immunogenic profiles and limited adverse effects.

Conflicts of Interests and Sources of Funding: D. H. is supported by the Association pour la Recherche sur le Cancer (ARC). A. S. is supported by the Ligue Nationale contre le Cancer (LIGUE). O. K. is supported by INSERM. L. G. is supported by the European Commission (Apo-Sys). G. K. is supported by the Ligue Nationale contre le Cancer (Equipes labellise'e), Agence Nationale pour la Recherche, AXA Chair for Longevity Research, European Commission (Apo-Sys, ArtForce, ChemoRes, ApopTrain), Fondation Bettencourt-Schueller, Fondation pour la Recherche Me'dicale, Institut National du Cancer, and Cance'ropo^le Ile-de-France. L. Z. is supported by Ligue contre le Cancer (e'quipe labellise'e), Fondation pour la Recherche Me'dicale, INFLACARE EU grant 2008, INCa, and from Fondation de France (2009Y2011). The authors have disclosed that they have no significant relationships with, or financial interest in, any commercial companies pertaining to this article. 


\section{REFERENCES}

1. Zitvogel L, Apetoh L, Ghiringhelli F, et al. The anticancer immune re-sponse: indispensable for therapeutic success? J Clin Invest. 2008;6: 1991Y2001.

2. Zitvogel L, Apetoh L, Ghiringhelli F, et al. Immunological aspects of cancer chemotherapy. Nat Rev Immunol. 2008;1:59Y73.

3. Shao H, Cai L, Grichnik JM, et al. Activation of Notch1 signaling in stromal fibroblasts inhibits melanoma growth by upregulating WISP-1. Oncogene. 2011; [Epub ahead of print April 25, 2011.].

4. Okada H, Mak TW. Pathways of apoptotic and non-apoptotic death in tumour cells. Nat Rev Cancer. 2004;8:592Y603.

5. Casares N, Pequignot MO, Tesniere A, et al. Caspase-dependent immu-nogenicity of doxorubicin-induced tumor cell death. J Exp Med. 2005; 12:1691Y1701.

6. Obeid M, Tesniere A, Ghiringhelli F, et al. Calreticulin exposure dictates the immunogenicity of cancer cell death. Nat Med. 2007;1:54Y61.

7. Obeid $M$, Panaretakis $T$, Joza $N$, et al. Calreticulin exposure is required for the immunogenicity of gamma-irradiation and UVC lightYinduced apoptosis. Cell Death Differ. 2007;10:1848Y1850.

8. Tesniere A, Schlemmer F, Boige V, et al. Immunogenic death of colon cancer cells treated with oxaliplatin. Oncogene. 4:482Y491.

9. Jung $S$, Unutmaz $D$, Wong $P$, et al. In vivo depletion of CD11c+ dendritic cells abrogates priming of CD8+ $T$ cells by exogenous cell-associated antigens. Immunity. 2002;2:211Y220.

10. Ghiringhelli F, Apetoh L, Tesniere A, et al. Activation of the NLRP3 inflammasome in dendritic cells induces IL1 betaYdependent adaptive immunity against tumors. Nat Med. 2009;10:1170Y1178.

11. Apetoh L, Ghiringhelli F, Tesniere A, et al. The interaction between HMGB1 and TLR4 dictates the outcome of anticancer chemotherapy and radiotherapy. Immunol Rev. 2007;220:47Y59.

12. Zitvogel L, Kepp O, Kroemer G. Decoding cell death signals in inflam-mation and immunity. Cell. 2010;140:798Y804.

13. Martins I, Kepp O, Galluzzi L, et al. Surface-exposed calreticulin in the interaction between dying cells and phagocytes. Ann N Y Acad Sci. 2010;1209:77Y82.

14. Panaretakis T, Joza N, Modjtahedi N, et al. The co-translocation of ERp57 and calreticulin determines the immunogenicity of cell death. Cell Death Differ. 2008;9:1499Y1509.

15. Panaretakis T, Kepp O, Brockmeier U, et al. Mechanisms of pre-apoptotic calreticulin exposure in cell death. EMBO J. 2009;5:578Y590.

16. Kepp O, Galluzzi L, Martins I, et al. Molecular determinants of immu-nogenic cell death elicited by anticancer chemotherapy. Cancer Metastasis Rev. 2011;30:61Y69.

17. Kepp O, Galluzzi L, Giordanetto F, et al. Disruption of the PP1/GADD34 complex induces calreticulin exposure. Cell Cycle. 2009;23:3971Y3977.

18. Kroemer G, Galluzzi L, Brenner C. Mitochondrial membrane permea-bilization in cell death. Physiol Rev. 2007;1:99Y163.

19. Rong $\mathrm{Y}$, Distelhorst CW. Bcl-2 protein family members: versatile reg-ulators of calcium signaling in cell survival and apoptosis. Annu Rev Physiol. 2008;70:73Y91.

20. Kroemer G, Galluzzi L, Vandenabeele P, et al. Classification of cell death: recommendations of the Nomenclature Committee on Cell Death 2009. Cell Death Differ. 2009;1:3Y11.

21. Vandenabeele $P$, Galluzzi L, Vanden Berghe $T$, et al. Molecular mech-anisms of necroptosis: an ordered cellular explosion. Nat Rev Mol Cell Biol. 2010;11:700Y714.

22. Berwin B, Delneste $Y$, Lovingood RV, et al. SREC-I, a type F scavenger receptor, is an endocytic receptor for calreticulin. J Biol Chem. 2004; 49:51250Y51257.

23. Duus K, Pagh RT, Holmskov U, et al. Interaction of calreticulin with CD40 ligand, TRAIL and Fas ligand. Scand J Immunol. 2007;5:501Y507.

24. Apetoh L, Ghiringhelli F, Tesniere A, et al. Toll-like receptor 4Ydependent contribution of the immune system to anticancer chemotherapy and ra-diotherapy. Nat Med. 2007;9:1050Y1059.

25. Andersson $\mathrm{U}$, Wang $\mathrm{H}$, Palmblad K, et al. High mobility group 1 protein (HMG-1) stimulates proinflammatory cytokine synthesis in human monocytes. J Exp Med. 2000;4:565Y570. 
26. Scaffidi P, Misteli T, Bianchi ME. Release of chromatin protein HMGB1 by necrotic cells triggers inflammation. Nature. 2002;6894:191Y195.

27. Bell CW, Jiang W, Reich CF III, et al. The extracellular release of HMGB1 during apoptotic cell death. Am J Physiol Cell Physiol. 2006; 6:C1318YC1325.

28. Gardai SJ, McPhillips KA, Frasch SC, et al. Cell-surface calreticulin initiates clearance of viable or apoptotic cells through trans-activation of LRP on the phagocyte. Cell. 2005;2:321Y334.

29. Sancho D, Joffre OP, Keller AM, et al. Identification of a dendritic cell receptor that couples sensing of necrosis to immunity. Nature. 2009; 7240:899Y903.

30. Kepp O, Galluzzi L, Kroemer G. Mitochondrial control of the NLRP3 inflammasome. Nat Immunol. 2011;3:199Y200.

31. Franchi L, Eigenbrod T, Munoz-Planillo R, et al. The inflammasome: a caspase-1Yactivation platform that regulates immune responses and disease pathogenesis. Nat Immunol. 2009;3:241Y247.

32. Latz E. The inflammasomes: mechanisms of activation and function. Curr Opin Immunol. 2010;1:28Y33.

33. Chekeni FB, Elliott MR, Sandilos JK, et al. Pannexin 1 channels mediate 'find-me' signal release and membrane permeability during apoptosis. Nature. 2010;7317:863Y867.

34. Elliott MR, Chekeni FB, Trampont PC, et al. Nucleotides released by apoptotic cells act as a find-me signal to promote phagocytic clearance. Nature. 2009;7261:282Y286.

35. Majeti R, Alizadeh AA, Tang C, et al. CD47 is an adverse prognostic factor and therapeutic antibody target on human acute myeloid leukemia stem cells. Cell. 2009;2:286Y299.

36. Jaiswal S, Jamieson $\mathrm{CH}$, Pang WW, et al. CD47 is upregulated on cir-culating hematopoietic stem cells and leukemia cells to avoid phago-cytosis. Cell. 2009;2:271Y285.

37. Chao MP, Jaiswal S, Weissman-Tsukamoto $\mathrm{R}$, et al. Calreticulin is the dominant pro-phagocytic signal on multiple human cancers and is counterbalanced by CD47. Sci Transl Med. 2010;2:63ra94.

38. Spisek R, Charalambous A, Mazumder A, et al. Bortezomib enhances dendritic cell (DC)-mediated induction of immunity to human myeloma via exposure of cell surface heat shock protein 90 on dying tumor cells: therapeutic implications. Blood. 2007;11:4839Y4845.

39. Sancho D, Mourao-Sa D, Joffre OP, et al. Tumor therapy in mice via antigen targeting to a novel, DC-restricted C-type lectin. J Clin Invest. 2008;6:2098Y2110.

40. Zitvogel L, Tesniere A, Kroemer G. Cancer despite immunosurveillance: immunoselection and immunosubversion. Nat Rev Immunol. 2006;10: 715Y727.

41. Mattarollo SR, Loi S, Duret H, et al. Pivotal role of innate and adaptive immunity in anthracycline chemotherapy of established tumors. Cancer Res. 2011;14:4809Y4820.

42. Pages F, Galon J, Dieu-Nosjean MC, et al. Immune infiltration in human tumors: a prognostic factor that should not be ignored. Oncogene. 2010; 8:1093Y1102.

43. Ma Y, Aymeric L, Locher C, et al. Contribution of IL-17Yproducing gamma delta T cells to the efficacy of anticancer chemotherapy. J Exp Med. 2011;3:491Y503.

44. Steinman RM, Mellman I. Immunotherapy: bewitched, bothered, and bewildered no more. Science. 2004;305:197Y200.

45. Banchereau J, Steinman RM. Dendritic cells and the control of immu-nity. Nature. 1998;6673:245Y252.

46. Albert ML, Sauter B, Bhardwaj N. Dendritic cells acquire antigen from apoptotic cells and induce class IYrestricted CTLs. Nature. 1998;6671: 86Y89.

47. Russo V, Tanzarella S, Dalerba $P$, et al. Dendritic cells acquire the MAGE-3 human tumor antigen from apoptotic cells and induce a class IYrestricted T cell response. Proc Natl Acad Sci U S A. 2000;5: 2185 Y2190.

48. Liu K, lyoda T, Saternus M, et al. Immune tolerance after delivery of dying cells to dendritic cells in situ. J Exp Med. 2002;8:1091Y1097.

49. Iyoda T, Shimoyama S, Liu K, et al. The CD8+ dendritic cell subset selectively endocytoses dying cells in culture and in vivo. J Exp Med. 2002;10:1289Y1302.

50. Maranon C, Desoutter JF, Hoeffel G, et al. Dendritic cells cross-present HIV antigens from live as well as apoptotic infected CD4+ T lympho-cytes. Proc Natl Acad Sci U S A. 2004;16:6092Y6097. 
51. Blachere NE, Darnell RB, Albert ML. Apoptotic cells deliver processed antigen to dendritic cells for cross-presentation. PLoS Biol. 2005;6:e185.

52. Hirschowitz EA, Foody T, Kryscio R, et al. Autologous dendritic cell vaccines for non-small-cell lung cancer. J Clin Oncol. 2004;14: 2808Y2815.

53. Obeid M, Tesniere A, Panaretakis $\mathrm{T}$, et al. Ecto-calreticulin in immu-nogenic chemotherapy. Immunol Rev. 2007;220:22Y34.

54. Schiavoni G, Sistigu A, Valentini M, et al. Cyclophosphamide synergizes with type I interferons through systemic dendritic cell reactivation and induction of immunogenic tumor apoptosis. Cancer Res. 2011;3:768Y778.

55. Pallis AG, Karamouzis MV. DNA repair pathways and their implication in cancer treatment. Cancer Metastasis Rev. 2010;4:677Y685.

56. Vitale I, Galluzzi L, Castedo M, et al. Mitotic catastrophe: a mechanism for avoiding genomic instability. Nat Rev Mol Cell Biol. 2011;6:385Y392.

57. Galluzzi L, Morselli E, Kepp O, et al. Targeting p53 to mitochondria for cancer therapy. Cell Cycle. 2008;13:1949Y1955.

58. Armeanu S, Bitzer M, Lauer UM, et al. Natural killer cellYmediated lysis of hepatoma cells via specific induction of NKG2D ligands by the histone deacetylase inhibitor sodium valproate. Cancer Res. 2005;14:6321Y6329.

59. Bartkova J, Horejsi Z, Koed K, et al. DNA damage response as a can-didate anti-cancer barrier in early human tumorigenesis. Nature. 2005; 7035:864Y870.

60. Gasser S, Orsulic S, Brown EJ, et al. The DNA damage pathway regu-lates innate immune system ligands of the NKG2D receptor. Nature. 2005;7054:1186Y1190.

61. Raulet DH, Guerra N. Oncogenic stress sensed by the immune sys-tem: role of natural killer cell receptors. Nat Rev Immunol. 2009;8: 568Y580.

62. Xue W, Zender L, Miething C, et al. Senescence and tumour clearance is triggered by $p 53$ restoration in murine liver carcinomas. Nature. 2007; 7128:656Y660.

63. Ramakrishnan R, Assudani D, Nagaraj S, et al. Chemotherapy enhances tumor cell susceptibility to CTL-mediated killing during cancer immu-notherapy in mice. J Clin Invest. 2010;4:1111Y1124.

64. Ghiringhelli F, Menard C, Puig PE, et al. Metronomic cyclophospha-mide regimen selectively depletes CD4+CD25+ regulatory $\mathrm{T}$ cells and restores $\mathrm{T}$ and NK effector functions in end stage cancer patients. Cancer Immunol Immunother. 2007;5:641Y648.

65. Viaud S, Flament $\mathrm{C}$, Zoubir $\mathrm{M}$, et al. Cyclophosphamide induces dif-ferentiation of $\mathrm{T}_{H} 17$ cells in cancer patients. Cancer Res. 2011;3:661Y665.

66. Proietti E, Greco G, Garrone B, et al. Importance of cyclophosphamide-induced bystander effect on T cells for a successful tumor eradication in response to adoptive immunotherapy in mice. J Clin Invest. 1998; 2:429Y441.

67. Schiavoni G, Mattei F, Di Pucchio T, et al. Cyclophosphamide induces type I interferon and augments the number of CD44(hi) T lymphocytes in mice: implications for strategies of chemoimmunotherapy of cancer. Blood. 2000;6:2024Y2030.

68. Nakahara T, Uchi H, Lesokhin AM, et al. Cyclophosphamide enhances immunity by modulating the balance of dendritic cell subsets in lymp-hoid organs. Blood. 2010;22:4384Y4392.

69. Salem ML, Al-Khami AA, El-Naggar SA, et al. Cyclophosphamide induces dynamic alterations in the host microenvironments resulting in a Flt3 ligand-dependent expansion of dendritic cells. J Immunol. 2010; 4:1737Y1747.

70. Salem ML, El-Naggar SA, Cole DJ. Cyclophosphamide induces bone marrow to yield higher numbers of precursor dendritic cells in vitro apable of functional antigen presentation to $T$ T cells in vivo. Cell Immunol. 2010;2:134Y143.

71. Salem ML, Kadima AN, El-Naggar SA, et al. Defining the ability of cyclophosphamide preconditioning to enhance the antigen-specific CD8+ T-cell response to peptide vaccination: creation of a beneficial host mi-croenvironment involving type I IFNs and myeloid cells. J Immunother. 2007;1:40Y53.

72. Borg C, Terme M, Taieb J, et al. Novel mode of action of c-kit tyrosine kinase inhibitors leading to NK cell-dependent antitumor effects. J Clin Invest. 2004;3:379Y388.

73. Menard C, Blay JY, Borg C, et al. Natural killer cell IFN-gamma levels predict long-term survival with imatinib mesylate therapy in gastroin-testinal stromal tumor-bearing patients. Cancer Res. 2009;8:3563Y3569. 
74. Shao C, Folkard M, Michael BD, et al. Targeted cytoplasmic irradia-tion induces bystander responses. Proc Natl Acad Sci U S A. 2004;37: 13495Y13500.

75. Formenti SC, Demaria S. Systemic effects of local radiotherapy. Lancet Oncol. 2009;7:718Y726.

76. Formenti SC, Demaria S. Effects of chemoradiation on tumor-host in-teractions: the immunologic side. J Clin Oncol. 2008;9:1562Y1563; author reply 1563.

77. Meng Y, Carpentier AF, Chen L, et al. Successful combination of local CpG-ODN and radiotherapy in malignant glioma. Int J Cancer. 2005; 6:992Y997.

78. Demaria S, Kawashima N, Yang AM, et al. Immune-mediated inhibition of metastases after treatment with local radiation and CTLA-4 blockade in a mouse model of breast cancer. Clin Cancer Res. 2005;2:728Y734.

79. Dewan MZ, Galloway AE, Kawashima N, et al. Fractionated but not single-dose radiotherapy induces an immunemediated abscopal effect when combined with antiYCTLA-4 antibody. Clin Cancer Res. 2009; 17:5379Y5388.

80. Matsumura S, Wang B, Kawashima N, et al. Radiation-induced CXCL16 release by breast cancer cells attracts effector T cells. J Immunol. 2008;5: 3099Y3107.

81. Schaue D, Comin-Anduix B, Ribas A, et al. T-cell responses to survivin in cancer patients undergoing radiation therapy. Clin Cancer Res. 2008;15:4883Y4890.

82. Lugade AA, Moran JP, Gerber SA, et al. Local radiation therapy of B16 melanoma tumors increases the generation of tumor antigen-specific effector cells that traffic to the tumor. J Immunol. 2005;12:7516Y7523.

83. Ma Y, Kepp O, Ghiringhelli F, et al. Chemotherapy and radiotherapy: cryptic anticancer vaccines. Semin Immunol. 2010;3:113Y124.

84. Ma Y, Conforti R, Aymeric L, et al. How to improve the immunogenicity of chemotherapy and radiotherapy. Cancer Metastasis Rev. 2011;1:71Y82.

85. Matsumura S, Demaria S. Up-regulation of the pro-inflammatory che-mokine CXCL16 is a common response of tumor cells to ionizing ra-diation. Radiat Res. 2010;4:418Y425.

86. Sluyter R, Shemon AN, Wiley JS. Glu496 to Ala polymorphism in the P2X7 receptor impairs ATP-induced IL-1 beta release from human monocytes. J Immunol. 2004;6:3399Y3405.

87. Arbour NC, Lorenz E, Schutte BC, et al. TLR4 mutations are associated with endotoxin hyporesponsiveness in humans. Nat Genet. 2000;2: 187Y191.

88. Tesniere A, Apetoh L, Ghiringhelli F, et al. Immunogenic cancer cell death: a key-lock paradigm. Curr Opin Immunol. 2008;5:504Y511.

89. Palucka K, Ueno H, Banchereau J. Recent developments in cancer vaccines. J Immunol. 2011;3:1325Y1331.

90. Belda-Iniesta C, Ibanez de Caceres I, de Castro J. Monoclonal antibodies for medical oncology: a few critical perspectives. Clin Transl Oncol. 2011; 2:84Y87.

91. Agarwala SS, Ribas A. Current experience with CTLA4-blocking mono-clonal antibodies for the treatment of solid tumors. J Immunother. 2010; 6:557Y569.

92. Gulley JL, Arlen PM, Bastian A, et al. Combining a recombinant cancer vaccine with standard definitive radiotherapy in patients with localized prostate cancer. Clin Cancer Res. 2005;11:3353Y3362.

93. Brody JD, Ai WZ, Czerwinski DK, et al. In situ vaccination with a TLR9 agonist induces systemic lymphoma regression: a phase I/II study. J Clin Oncol. 2010;28:4324Y4332. 


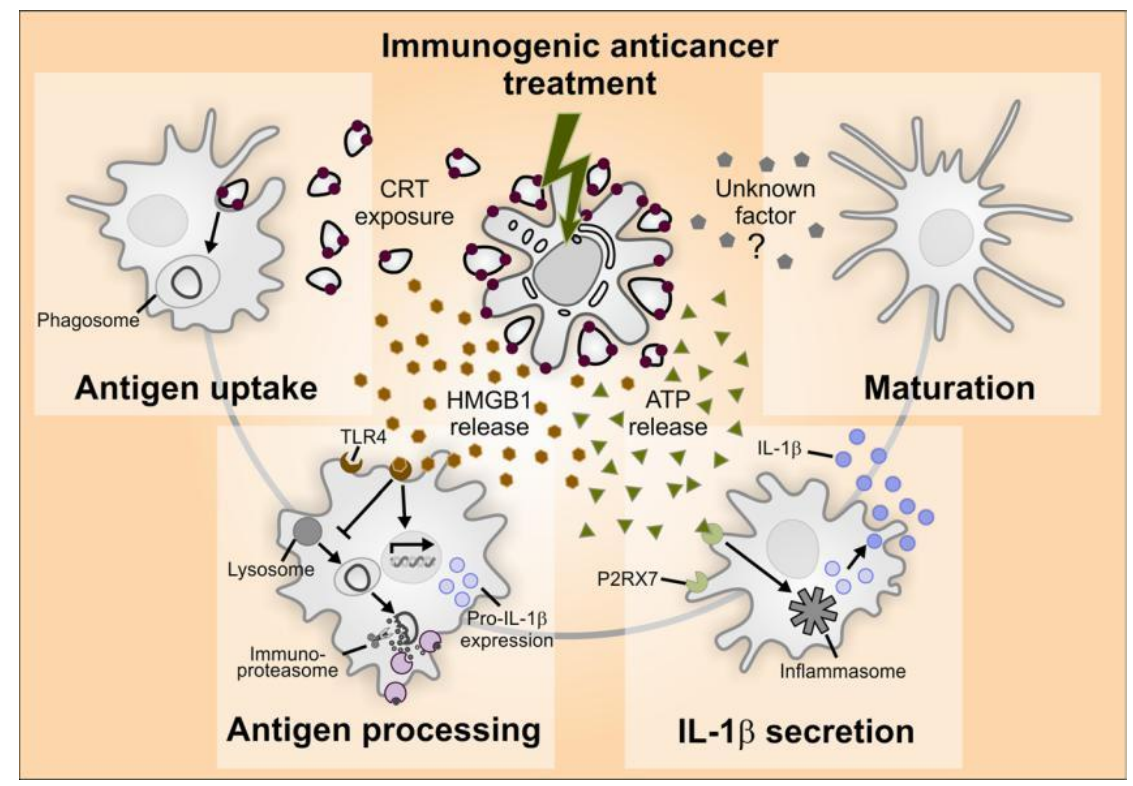

FIGURE 1. Immunogenic signals emitted by dying cells form a spatiotemporal code unlocking DCs to mount a potent immune response toward tumor cells. (i) Early exposure of ecto-CRT by dying tumor cells, which facilitates engulfment by DCs. (ii) HMGB1 released from dying cells binds to TLR4 on DCs, thus favoring antigen cross-presentation and up-regulating proYIL-A (proYIL-1A).

(iii) ATP liberated from dying cells binds to the purinergic receptor P2RX7 on DCs, activates the NLRP3 inflammasome, and leads to the secretion of active IL-1A, which polarizes CD8+ T cells toward IFN-F production. (iv) An additive DC maturation factor remains to be characterized. 


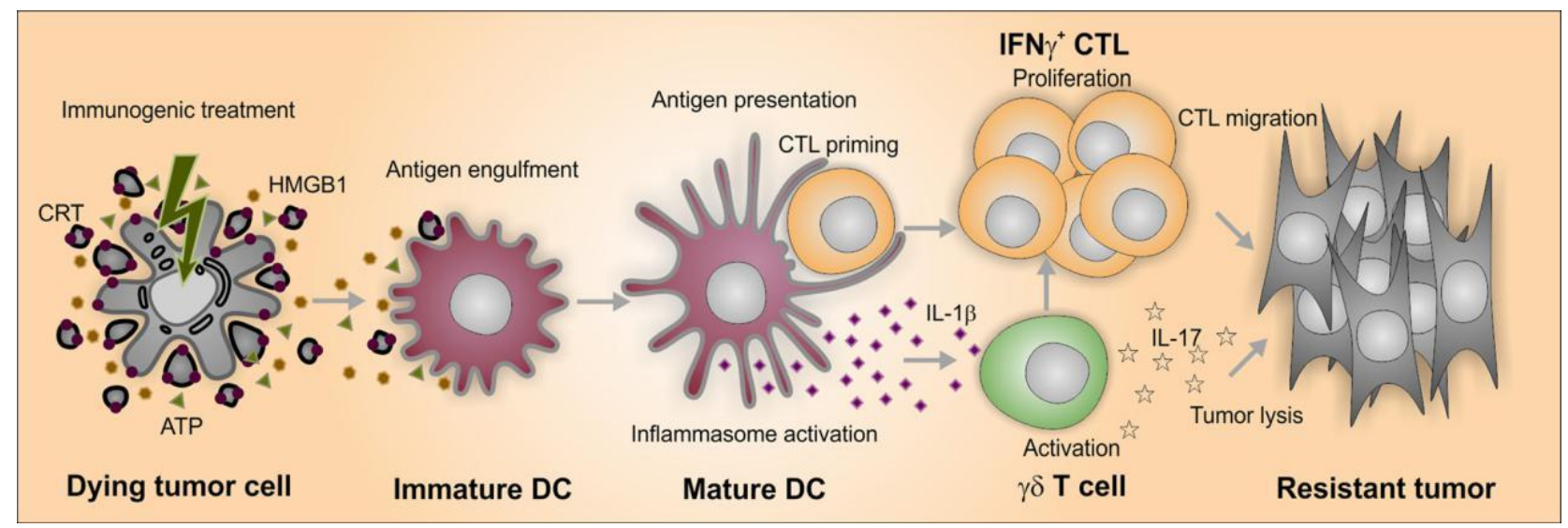

FIGURE 2. Precise orchestration of antitumor T-cell responses elicited following ICD: After (immunogenic) chemotherapy, tumor material is phagocytosed by DCs. These later are also activated by ICD signals emitted by dying tumor cells. Within 2 days, IL-17Yproducing FC T cells are recruited to the tumor bed in an IL-1AYdependent manner. Their arrival precedes and correlates with the IFN-FYproducing $\mathrm{CD}^{+}{ }^{+}$cells infiltration, which is critical for tumor eradication. 


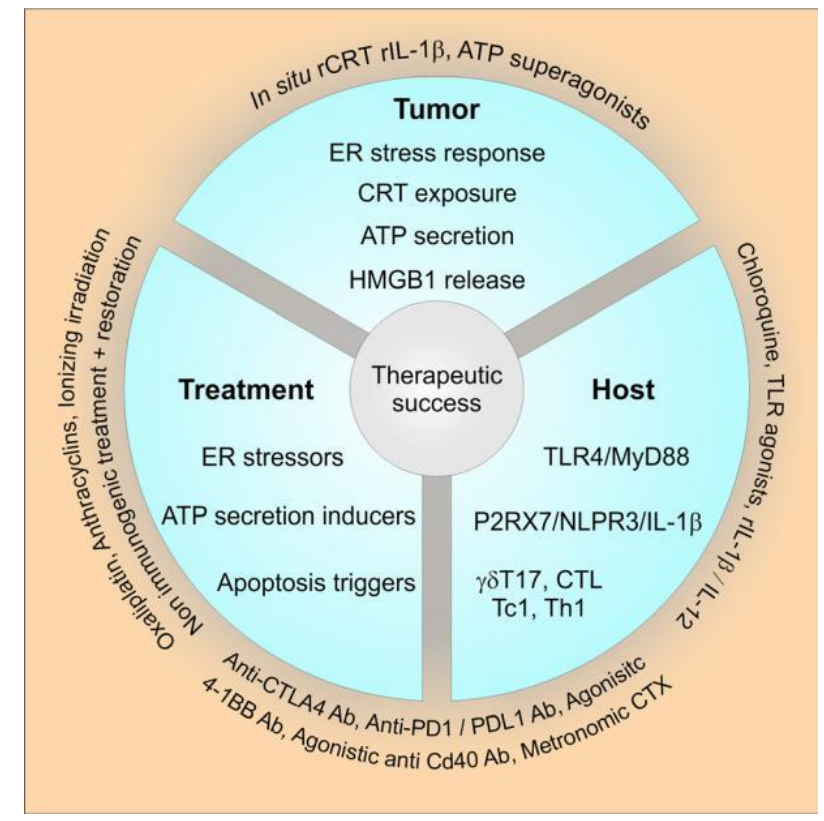

FIGURE 3. Schematic view of tailored anticancer regimens: To achieve therapeutic success, (i) the anticancer regimen should be able to induce ICD, that is, to induce an ER stress before cell death and ATP release. Nonimmunogenic cytotoxic drug can be combined with ER stressors to restore immunogenicity. (ii) The tumor of the patient should have conserved the intrinsic capacities to emit all the immunogenic signals. If not, the defective signals could be identified and then compensate by recombinant CRT or rIL-1A or ATP superagonists. (iii) The loss-of-function mutation of key receptors involved in the perception of ICD signals might also be compensated by triggering alternative TLR pathway or supplementation with the appropriate cytokine. (iv) The combination of immunotherapy and immunogenic chemotherapy enhances the vaccine-like effect of chemotherapy and radiotherapy by overcoming the tumor-induced immunosuppression. Thus, tailored anticancer regimens should be designed by taking into account the genetic background of both the tumor and the host, with an aim to correctly unlock the immune system to obtain the complete eradication of the tumor and long-term tumor-free survival. 